\title{
INTEGRATING THE PRODUCT DEVELOPMENT PROCESS IN SCIENTIFIC RESEARCH. BRIDGING THE RESEARCH- MARKET GAP
}

\author{
Mesa, David; Thong, Christine; Ranscombe, Charles; Kuys, Blair \\ Swinburne University of Technology
}

\begin{abstract}
Science and technology generated by Universities has many challenges in reaching commercial product applications, as has been explored in a range of literature. Product design has been identified to add value through various types of contributions in addressing these challenges; however, there remains a gap in literature to explore how and when product development activities can practically be applied to technology development.

This paper furthers the idea that the product development process can help bridge the gap between the laboratory and commercial applications by proposing a framework for how Ulrich and Eppinger's product development process can integrate with the STAM technology development model. This is a significant step towards understanding how in practice these disciplines can work together to bring science and technology from the laboratory to products in the marketplace.
\end{abstract}

Keywords: Technology, New product development, Design methods, Collaboration, Science

\section{Contact:}

Mesa, David

Swinburne University of Technology

Department of Interior Architecture and Industrial Design

Australia

dmesa@swin.edu.au 


\section{INTRODUCTION}

Explaining the importance of open innovation and university-industry collaboration, Mansfield and Lee (1996) argue that scientific knowledge produced by university research has become increasingly important to product innovation and new business development. However, although the importance of transferring scientific research to market is clear, evidence of success in doing this is minimal and literature shows that only a few research projects actually manage to reach the marketplace (Wessner, 2005). The low success of scientific intellectual property (IP) migration is creating dissatisfaction in society and, in some countries, industry is becoming more hesitant to provide funding for new university collaborations (OECD, 2017). Literature defines the big gap between scientific research and market as "the valley of death" (Wessner, 2005).

The problem of commercialising scientific discoveries has been widely explored, however it is still an issue and existing literature does not provide a clear description of the activities needed for the transition from the scientific laboratory to market. This paper proposes a framework with the activities required to take early-stage technologies - being developed in science research contexts - to the marketplace, focusing on the role that science and design (product design) play throughout the whole process of technology development. The authors argue that technology development requires the involvement of multiple disciplines and, based on existing literature, propose a framework to describe the activities required for preparing technologies to the market. This work is a first step of a larger study seeking to understand the role that product designers play in science commercialisation.

Product development refers to the set of activities beginning with the identification of an opportunity and finishing with the production and delivery of the product (Eppinger and Ulrich, 2015). Design, specifically, will be understood as the activities within the product development process (PDP) that are required to deliver a detailed description of an artefact to be made (Cross, 2008).

As the development of products is the domain of design methodology, and products are required to embody technologies in the market, this paper seeks to propose a framework for science-design collaboration through the question:

How can the process to develop products be integrated with the phases of technology development to facilitate science-design collaborations?

To answer this question, this paper begins by examining the literature explaining the inherent problems with commercialising scientific research. It also analyses the models that have been created based on successful technology migrations to market. In addition, it explores the relations between design and science methodologies, and discusses the role of design in the process of transforming the knowledge acquired by scientists into products. This paper then presents the method used for mapping activities in a framework that integrates product design methods into the phases of technology development. The developed framework identifies the activities that are in the domain of science and the activities that are part of the PDP. With this framework, the authors suggest multidisciplinary collaborations to increase science migration to market and as an alternative to obtain more research funding from industry. However, they defend the idea that not all the university research should be driven by commercialisation.

\section{THE CHALLENGE OF COMMERCIALISING SCIENCE}

Changes to technology and knowledge in recent decades have forced universities to redesign their organisational strategy, migrating to more industry-led research aiming to generate more impact on society, the market and the economy of nations (Etzkowitz et al., 2000).

While the United States and Japan (and more recently the Republic of Korea) remain exemplar countries in taking technologies from scientific research to market thanks to large federal funding (Wessner, 2005, Livesey et al., 2006) and government priorities, studies show that in countries with world-class research, there is a big gap to commercialisation (Livesey et al., 2006, Minshall et al., 2007) and university-industry collaboration hesitancy (OECD, 2017). This gap between university IP produced by research and its commercialisation is defined by literature as "the valley of death".

According to Markham et al. (1991), inside corporate structures, an employee has to take the role of product 'champion' to cross the valley of death. In the case of universities, the gap seems bigger than that in industry; universities lack the developing and marketing experience of large firms. The authors explain that the skillset needed to take a technological discovery from research to a commercial product is complex, and the person taking this role must be moved by passion. Markham et al. (1991) note that 
despite this intense effort, normally there are not sufficient rewards within organisations for these champions - similar to what happens with the lack of incentives for scientists commercialising technologies in universities. Markham (2002) proposes nine stages that are required to bridge the 'valley of death' (see Figure 1) but he does not provide detail of the activities in these stages or the discipline responsible for them. Later in the paper, a product development process is presented (see Figure 3), showing clear similarities to the stages for bridging the valley proposed by Markham.

In universities, scientists developing technologies usually take the role of 'champions'; however, their lack of business experience prevents them from succeeding (Würmseher, 2017). However, design theory suggest that the transformation of ideas into commercial products should be done by interdisciplinary teams with different skillsets; mainly covering the marketing, design and manufacturing of the product. (Eppinger and Ulrich, 2015).

The solutions proposed by literature to bridge the valley of death do not explain the process to develop an early-stage technology (Markham, 2002, Wessner, 2005). However, the methodology of design can provide an alternative way to bridge the valley of death covering the activities required to transform a technology application idea into a product. This paper argues that the PDP activities should be integrated early in scientific research projects, helping throughout the whole valley of death; building the concept, demonstrating potential and developing the product.

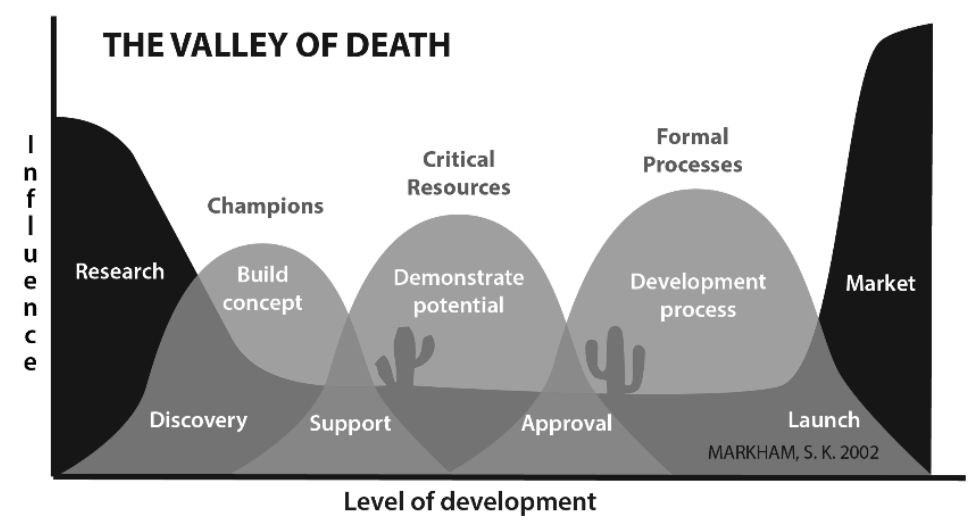

Figure 1. The valley of death model and stages to bridge it (Markham 2002)

Wessner (2005) states that universities are facing this big challenge in the early stages of technological IP migration to market, mainly as a result of the significant financial investment that is needed. Various sources of these funds may be government (Branscomb and Auerswald, 2002, Wessner, 2005), industry partnership (O'shea et al., 2005) or angel investors (Würmseher, 2017). The reason for which so much government funding is needed is that early-stage technologies face a high risk of failure, and private investors therefore are hesitant to invest (Wessner, 2005). Wessner (2005) explains that in order to be able to attract government support, new technologies must target clear applications and university researchers must effectively explain the impact they will have on the market.

For Markman et al. (2005), the success of universities taking technologies to market is directly related to the innovation speed (the time between technology discovery and commercialisation). Zappe (2013) on the other-hand, mentions that the best way to close the large gap of technology commercialisation is a better understanding of the needs, motivations and limitations of both industry and universities.

By analysing literature's suggestions for the causes of this IP migration issue, it is conceivable to claim that university scientific groups will have more chances of receiving funding for their research if they search for applications to solve market and society needs, from both industry partners and government to articulate the expected impact on the economy. In the same order of ideas, if a market focus can attract more funding in research, it will increase the chances of bridging the valley of death. The following sections of this paper present works with evidence of how designers collaborate with scientists, to show how a framework with integrated design activities into a scientific domain can feed research with the necessary market perspective.

\subsection{Challenges of the different routes to market}

To create a framework for technology development in universities it is important to understand the available routes for technology transfer and the problems surrounding this topic. 
Traditionally, scientists can choose between two main routes for commercialising their IP: licensing or creating university spin-offs (Minshall et al., 2007). To help scientists with this process, Technology Transfer Offices (TTOs) are created. TTOs are established to manage and protect the IP of universities in response to the open innovation models and the migrations to industry (Siegel et al., 2004). The main roles of these offices are promoting faculty consultancy, licensing university IP through established firms, building spin-off ventures around university IP and providing support for the creation of start-ups (Minshall et al., 2007). Authors analysing the impact of TTOs have identified that the incentives and distributions of royalties to the inventors are key for IP migration (Friedman and Silberman, 2003, Siegel et al., 2003, Bradley et al., 2013, Würmseher, 2017), while according to Markman et al. (2004), what encourages the technology transfer are the incentives to the tech transfer officers.

Würmseher (2017) describes three different entrepreneurial approaches that scientists can take according to their career expectations. First, the inventor entrepreneur; where a scientist wants the role of entrepreneur when co-funding with other inventors. In this model, the biggest barrier is that the scientist usually lacks business skills for commercialising the technology (Bradley et al., 2013, Würmseher, 2017). Second, the surrogate entrepreneur; which is ideal if the scientist does not want to leave the research life-style but requires an entrepreneur with business experience attracted to the potential of the technology. Third, the angel investor; where the scientist chooses an associate with complementary skills to join the venture (Würmseher, 2017).

In summary, the problems of university technology commercialisation identified by literature are:

Scientific projects with insufficient financial investment, technologies lacking clear market applications, slow development time (lack of innovation speed), lack of understanding and communication in universitybusiness collaborations, scientists lacking business skills when trying to start companies, and a lack of university services to help scientists with advice for the development of their technology.

In the current model, TTOs provide legal support and business advice to scientists, but there are not clear resources to develop applications that are more attractive to the market. Maia and Claro (2013) determine that the most critical phase of technology commercialisation is between invention and product development, when the application concepts are created and verified and appropriate markets are identified. The integration of design methods in scientific research may be a solution for giving market focus in these critical stages.

\subsection{Lessons from industry}

Technology innovation management authors explain that the first stages of technology development are critical for commercialisation. In these phases, strategy and planning are key for developing technology products (Brem and Voigt, 2009, Caetano and Amaral, 2011). Koen et al. (2001) explain that commercial opportunities are recognised in the front-end of innovation, when usually the process for selecting ideas is chaotic and unclear. In early stages, many opportunities are identified; they need to be prioritised and selected according to the strategy (Koen et al., 2001). Brem and Voigt (2009) propose using creative methods for collecting ideas (design thinking methods); such as future-scenario workshops with experts to predict the result of taking certain technologies to market. These workshops consider sociocultural, legal, political, economic, technological and environmental influences.

Caetano and Amaral (2011) propose three stages for technology development after a technology idea has been selected; first, a technology needs to go through market prioritisation to search for possible market partners. Secondly, the potential products need to be identified and prioritised. Finally, this should be followed by the identification of potential technological and financial partners.

Existing literature studying technology companies suggests defining a clear strategy, analysing the market and imagining future scenarios as initial activities to be conducted on technology development.

To be able to match activities with a specific moment of the technology development, a classifying method must be defined. There are not many available models to classify the maturity of technologies. For this purpose, NASA technology readiness levels (TRL) by Mankins (1995) is popular within the literature despite it was developed specifically for an aerospace context.

On the other-hand, Phaal et al. (2011) present a framework for mapping industrial emergence from studying and comparing the evolution of more than 25 technologies in different scientific fields. The authors classify phases and the transitions between science-technology-application-market to propose the STAM model (see Figure 2). They also identify the milestones that the technologies need to achieve in each phase, and they call these milestones 'demonstrators'. Phaal et al. (2011) present a detailed explanation of technology maturity stages and their model is also useful for describing the transition of the 
technology into a market environment. For these reasons, this model is used as reference for classifying design and science activities.

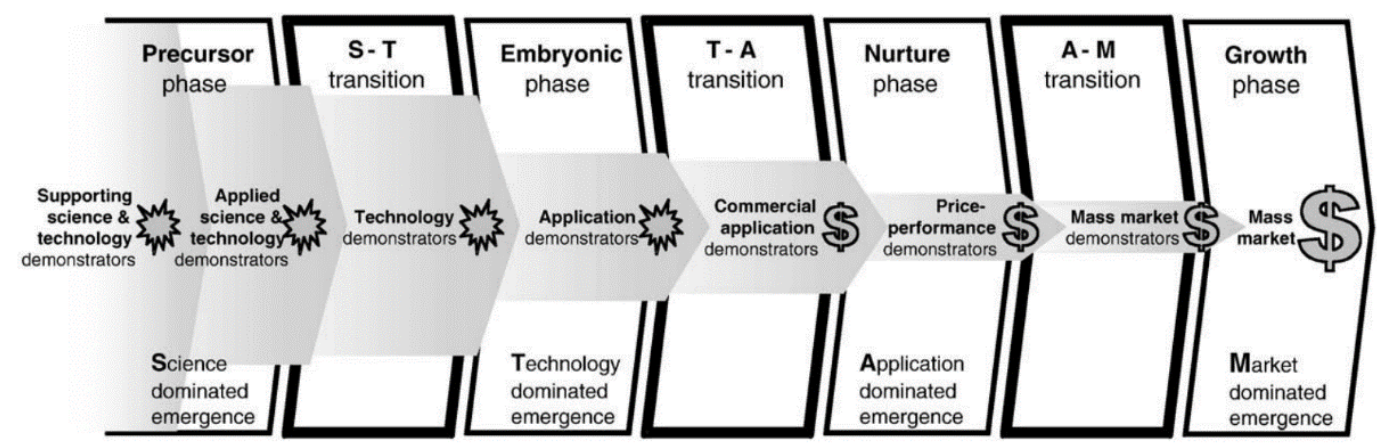

Figure 2. Phases, transitions and demonstrators associated with technology-based industrial emergence (Phaal et al., 2011)

\section{DESIGN RELATION WITH SCIENCE}

Stember (1991) defines interdisciplinary work as a collaborative approach between different disciplines that seeks broader understanding of processes and problems through diversity and unity. In the context of science and design, it is important to understand how they relate and how they differ, to recognise how each of them is relevant in the process of bridging the gap between research and market.

According to Roozenburg and Eekels (1995), the acquisition of knowledge is the domain of science, and the translation of this knowledge into products or material reality is the domain of design. While scientific enquiry is focused on discovering what already exists, design - in contrast — claims invention and novelty (Rust, 2004). However, despite the commercialisation of technologies requiring both generation of knowledge and embodying that knowledge into applications and products, few studies explore design and science collaborations in detail.

Moultrie (2015) classifies the objects, artefacts or concepts that interact as intermediaries between different actors and audiences as demonstrators. In the scientific research context, the author found that transitioning technologies to market most of the demonstrators are in the domain of design.

Simeone et al. (2016) focuses on analysing designers' ability to act as translators between different stakeholders in academic entrepreneurship projects. Similarly to Moultrie, Simeone et al. (2016) explain that design artefacts (sketches, visualisations, prototypes) can translate different needs and interests into a shared language that allows coordinated ways of working in multidisciplinary teams and audiences. This ability to create shared language and represent ideas seems to be key to solving the communication barriers between science and industry identified by Zappe (2013).

\subsection{Designers collaborating with scientists}

Rust (2004) explains that designers' ability to imagine new scenarios and create practical environments can also help scientists to communicate their research to broader audiences. In addition, designers' tools and skills help them to visualise their research problems from different perspectives.

Other works have also identified contributions of designers to scientific research; Moody (1980) mentions that designers' ability to communicate ideas can help scientific researchers obtaining resources for their projects. Driver et al. (2011) identify prototyping for quick testing ideas, visualising scenarios of use, producing devices/processes/spaces to enhance scientists' research capabilities and performing user and market research to enhance the commercial potential of the outputs of scientific research, as the major contributions a designer can bring to the early stages of scientific research. With a qualitative research approach, Moultrie (2015) identifies contributions with the demonstrators in the domain of design and Simeone et al. (2016) highlight designers' ability to work as translators in multidisciplinary projects. Specifically in scientific material development, studies have identified that designers can contribute testing properties and manufacturing processes for materials, in addition to exploring commercial applications for them (Kotlarewski et al., 2016, Thong and Kuys, 2012).

These contributions clearly show that science-design collaboration is important to increase the commercial output of scientific research, and can solve many of the problems surrounding the valley of death. The lack of clarity in the interaction of these disciplines and the activities that are needed to 
develop a technology, seem to be important barriers for technology commercialisation. The framework that will be presented in this paper seeks to make scientists and designers aware of the importance of multiple disciplines in the migration of university knowledge to the market.

\section{METHOD FOR INTEGRATING THE PRODUCT DEVELOPMENT PROCESS IN SCIENTIFIC RESEARCH}

The works reviewed in this paper show that design and science need each other. However, in the process of developing technology it is not clear which activities belong to science and which belong to design methodology (PDP), nor how the participation of disciplines changes while the project matures. Despite the differences between scientific and design methods, it is necessary to understand that there is a shared responsibility in technology development. A detailed framework for the development of scientific knowledge into market products is required to guide how this can occur in practice by identifying the roles and activities of the different disciplines involved. This section presents the activities that have been mapped with the stages of technology development and the discipline responsible for them. The phases, transitions and demonstrators associated with technology-based industrial emergence by Phaal et al. (2011) (STAM model) have been used to define the maturity stage of the technology. On the other-hand, the product development process (PDP) by Eppinger and Ulrich (2015) is used for defining most of the activities in the creation of a product to embody the technology.

For technology-push products, those emerging from science to develop a market, Eppinger and Ulrich (2015) propose a modified product development process (see Figure 3), starting by selecting an appropriate market before applying their generic model.

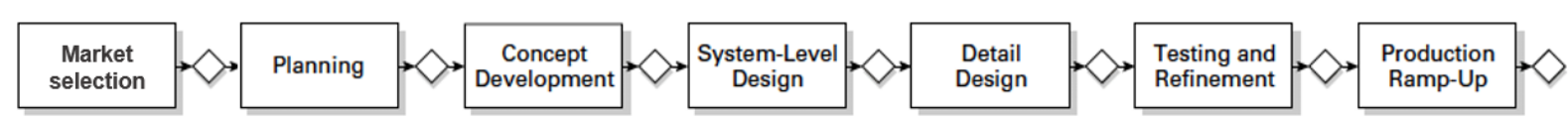

Figure 3. Product development process for tech-push projects (Eppinger and Ulrich, 2015)

The framework we propose gathers and represents structured design methods with a list of activities to consider. It remains general to provide guidance and assistance in a variety of scenarios where the technology can be quite different. As there is a lot of uncertainty in the early stages of development, the framework suggests going back in stages when the evaluation of previous ideas is required.

For defining which activities should match the phases from science to market (STAM), the studies from different research areas presented in this paper were compared and analysed. Strategy definition was added as the first stage of technology development as suggested by the technology innovation literature.

In the framework below, we propose responsibilities of the PDP and scientists, matched to the STAM phases described by Phaal et al. (2011) (see Table 1 to Table 5 and Figure 4).

Precursor Phase: Activities to establish the supporting scientific phenomena and/or the underpinning of technology platform. The stages in this phase result in supporting science and technology demonstrators that can attract the interest of potential investors (Phaal et al., 2011). This phase may take quite a lot of time and is based on the scientist's experience. Design plays an assisting role.

Table 1. Activities during precursor phase

\begin{tabular}{l|l} 
PDP Stage: & Strategy definition \\
\hline $\begin{array}{l}\text { Design } \\
\text { Shared, }\end{array}$ & $\begin{array}{l}\text { Moderate the design thinking workshops for future scenarios. } \\
\text { Business } \\
\text { opportunities and threats of the new research idea (technology) and the scientific } \\
\text { research group (external experts from other fields should participate). }\end{array}$ \\
\hline $\begin{array}{l}\text { Science } \\
\text { Demonstrate feasibility of the scientific phenomenon. }\end{array}$ \\
\hline PDP Stage: & Market selection \\
\hline Marketing & $\begin{array}{l}\text { Research and propose potential markets and environmental and political policies that } \\
\text { may affect the technology. }\end{array}$ \\
\hline $\begin{array}{l}\text { Shared } \\
\text { Science }\end{array}$ & $\begin{array}{l}\text { Market selection based on the strategy defined. } \\
\text { Demonstrate feasibility of the scientific phenomenon. }\end{array}$
\end{tabular}


Science-Technology transition: Activities to demonstrate the feasibility of a scientific phenomenon to support a new market-directed platform, showing the possibilities of integrating the technology into an application-specific system. Applied science and technology demonstrators result from this phase. Design plays an active role in this phase understanding market and user needs and conceptualising ideas.

\section{Table 2. Activities during science-technology transition}

\begin{tabular}{|c|c|}
\hline \multicolumn{2}{|c|}{ PDP Stage: Planning } \\
\hline Design & Generate concepts of technology platforms and applications. \\
\hline Shared & $\begin{array}{l}\text { Identify the technology state of the art to analyse opportunities. Define product design } \\
\text { specifications for a selected application and select a team according to them. }\end{array}$ \\
\hline cience & ments to test the technology. \\
\hline
\end{tabular}

Embryonic phase: Activities to improve the reliability and performance of the market-directed technology to a point where it can be demonstrated in a market-specific environment. Application demonstrators result from this phase. Design starts playing a more time-demanding role.

Table 3. Activities during embryonic phase

\begin{tabular}{l|l|l|} 
PDP Stage: & Concept development \\
$\begin{array}{l}\text { Design, } \\
\text { Marketing }\end{array}$ & $\begin{array}{l}\text { Identify costumer needs and competitors. Generation of industrial design concepts. } \\
\text { Build and test experimental prototypes. }\end{array}$ \\
\hline Shared & Investigate feasibility of product concepts. \\
\hline Science & Improve and test the technology reliability and performance.
\end{tabular}

Technology-Application transition: Activities to develop the technology and application to a point where commercial potential can be demonstrated through revenue generation. This phase represents the transition where design methodology takes the main role of the project and the resulting commercial application demonstrators represent the transition to an industry and market environment.

\section{Table 4. Activities during technology-application transition}

\begin{tabular}{|c|c|}
\hline \multicolumn{2}{|c|}{ DPP Stage: System-level design } \\
\hline $\begin{array}{l}\text { Design, } \\
\text { Engineering }\end{array}$ & $\begin{array}{l}\text { Define plan for product options or variations, product architecture, sub- } \\
\text { systems and interfaces. Components selection. Preliminary engineering. } \\
\text { Identify suppliers of components. Define assembly. }\end{array}$ \\
\hline $\begin{array}{l}\text { Shared, } \\
\text { Business, Legal }\end{array}$ & $\begin{array}{l}\text { Test technology scalability and production costs. Define business plan and IP } \\
\text { management / commercialisation strategy. }\end{array}$ \\
\hline Science & Assistance integrating the technology in the application. \\
\hline \multicolumn{2}{|c|}{ PDP Stage: Detail design } \\
\hline $\begin{array}{l}\text { Design, } \\
\text { Marketing } \\
\text { Engineering }\end{array}$ & $\begin{array}{l}\text { Components design and engineering. Define market plan. Define geometry, } \\
\text { materials, tolerances, manufacturing processes and quality assurance } \\
\text { processes. }\end{array}$ \\
\hline Shared & Build prototypes. \\
\hline Science & Science plays an assisting role. \\
\hline \multicolumn{2}{|c|}{ PDP Stage: Testing and refinement } \\
\hline $\begin{array}{l}\text { Design, } \\
\text { Engineering }\end{array}$ & $\begin{array}{l}\text { Field-testing of prototypes. Test performance, reliability and durability. } \\
\text { Implement design changes. Refine fabrication and assembly. }\end{array}$ \\
\hline $\begin{array}{l}\text { Shared, } \\
\text { Marketing, } \\
\text { Business, Legal }\end{array}$ & $\begin{array}{l}\text { Develop a marketing and sales plan. Obtain regulatory approvals and asses } \\
\text { environmental impact. }\end{array}$ \\
\hline Science & $\mathrm{s}$ an assisting role. \\
\hline
\end{tabular}

Nurture Phase: Activities to improve the price and performance of the application to a point where sustainable business potential can be demonstrated. Scientists involvement at this stage is defined by the commercialisation route defined. The design role is the improvement of the product and manufacturing processes. This is the last stage of the product development process. 


\section{Table 5. Activities during nurture phase}

PDP Stage: Production ramp-up

Design, Place early production with key costumers. Evaluate user experience. Full operation of Sales the production system.

Shared Project review.

Application-Market transition: Activities to translate price-performance demonstrators into a market with mass growth potential. Science and design participation depend on the business plan.

Growth phase: Market, commercial and business development leading to sustainable industrial growth.

Based on this synthesis of design methodology and science activities, Figure 4 maps the sequence of these activities in relation to one another.

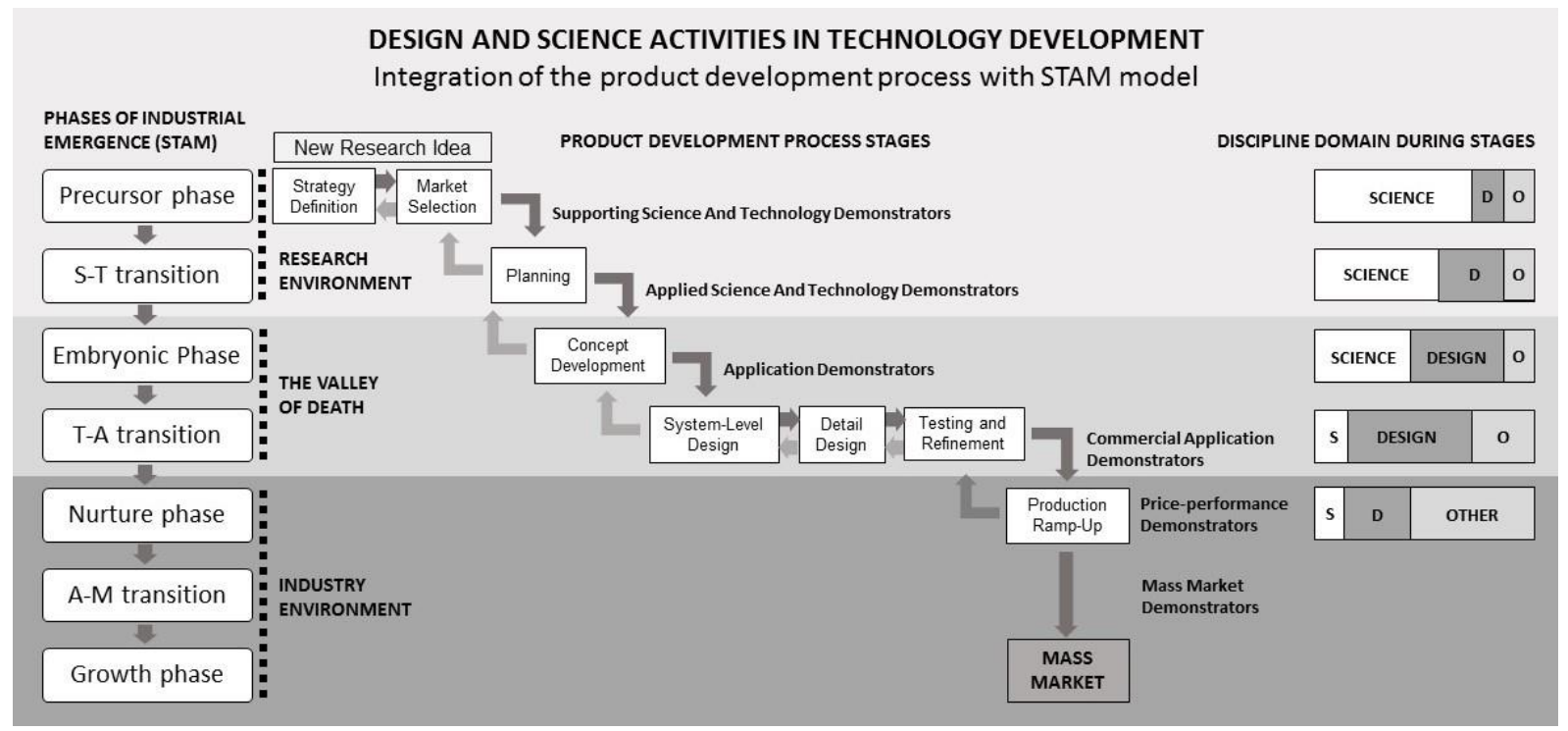

Figure 4. Activities in the domain of design methodology and science during technology development.

\section{CONCLUSIONS}

This paper has explored the literature explaining the reasons for the low success of technology commercialisation in university scientific environments. Specifically, it has presented the problems in technology migration: scientists' lack of business skills, lack of funding, problems in universityindustry communication, innovation speed, lack of incentives and lack of market focus. This paper has also presented literature explaining the potential of science-design collaborations for solving these issues and has proposed a framework to facilitate multidisciplinary collaborations and guide the process of technology development with the inclusion of design and other disciplines at the very beginning. Further research is required to identify the responsibility of different disciplines in the migration of technologies to market in order to understand how to address these problems in practice. The framework presented is based on an integration of models of technology classification (STAM) and the product development process, and it is informed by literature exploring technology innovation. It provides a list of roles and activities that are proposed to be conducted by design, science and other disciplines, which are necessary for further research to test this through application. This framework results in an adapted product development process; aimed to fit within science disciplines with engineered objects or products as outputs.

\section{DISCUSSION}

The framework may require different activities in other fields, such as biotechnology, where the outputs do not need to be embodied in an engineered physical form. The PDP focuses on complex engineered products; the proposed framework covers the same type of projects. 
It can take decades for a technology to go through all the phases of development (Phaal et al., 2011). On the other-hand, Eppinger and Ulrich (2015) mention that the product development process in industry can take between one to ten years. More exploration and testing is needed to understand the adequate timing for designers' participation in scientific projects and to construct a model to facilitate these interactions in the university structure -with adequate incentives for each involved discipline.

It is important to highlight that the development of products is an interdisciplinary activity (Eppinger and Ulrich, 2015); each research project requires teams with different skills and talents, and the cooperation between the team members is essential. Eppinger and Ulrich (2015) explain that usually projects require the participation of the whole firm. As the framework presented in this paper aims to fit a university research environment with a very different organisational structure than commercial firms, the activities are classified as in the domain of science or design methodology. It is important to acknowledge that incorporating the different disciplines of the PDP into science projects may strengthen the technology development, especially transitioning to industry environments.

This framework proposes significant inclusion of design and other disciplines in the phases before the market migration, where scientists obtain funding for their research and own the IP. The incorporation of design methodology in the technology development process requires resources and collaboration. Who will facilitate these resources? Who will start the collaborations that are needed to develop technologies? What are the incentives for scientists to spend resources in the PDP activities or developing their technologies? How do you make scientists aware of the value of design methodology? Under the current university environment it is hard to answer these questions. However, this field presents an opportunity for further research that may increase the research impact that society is expecting from academia, and the proposed framework provides a strategy upon which to do so.

\section{ACKNOWLEDGEMENTS}

We would like to thank the scientists in the LNI group from Swinburne University of Technology's Centre for Micro-Photonics and Design Factory Melbourne for making this collaboration study possible.

\section{REFERENCES}

Bradley, S.R., Hayter, C.S. and Link, A.N. (2013), "Proof of concept centers in the United States: An exploratory look", The Journal of Technology Transfer, Vol. 38 No. 4, pp. 349-381, available: http://dx.doi.org/10.1007/s10961-013-9309-8.

Branscomb, L. and Auerswald, P.E. (2002), "Between invention and innovation an analysis of funding for early-stage technology development".

Brem, A. and Voigt, K.-I. (2009), "Integration of market pull and technology push in the corporate front end and innovation management-Insights from the German software industry", Technovation, Vol. 29 No. 5, pp. 351367, available: http://dx.doi.org/10.1016/j.technovation.2008.06.003.

Caetano, M. and Amaral, D.C. (2011), "Roadmapping for technology push and partnership: A contribution for open innovation environments", Technovation, Vol. 31 No. 7, pp. 320-335, available: http://dx.doi.org/10.1016/j.technovation.2011.01.005.

Cross, N. (2008), Engineering Design Methods: Strategies for Product Design, Wiley.

Driver, A., Peralta, C. and Moultrie, J. (2011), "Exploring how industrial designers can contribute to scientific research", International Journal of Design, Vol. 5 No. 1.

Eppinger, S. and Ulrich, K. (2015), Product design and development, McGraw-Hill Higher Education.

Etzkowitz, H., Webster, A., Gebhardt, C. and Terra, B.R.C. (2000), "The future of the university and the university of the future: evolution of ivory tower to entrepreneurial paradigm”, Research policy, Vol. 29 No. 2, pp. 313-330, available: http://dx.doi.org/10.1016/S0048-7333(99)00069-4.

Friedman, J. and Silberman, J. (2003), "University technology transfer: do incentives, management, and location matter?", The Journal of Technology Transfer, Vol. 28 No. 1, pp. 17-30, available: http://dx.doi.org/10.1023/A:1021674618658.

Koen, P., Ajamian, G., Burkart, R., Clamen, A., Davidson, J., D’Amore, R., Elkins, C., Herald, K., Incorvia, M. and Johnson, A. (2001), "Providing clarity and a common language to the "fuzzy front end"', Research-Technology Management, Vol. 44 No. 2, pp. 46-55, available: http://dx.doi.org/10.1080/08956308.2001.11671418.

Kotlarewski, N.J., Kuys, B. and Thong, C. (2016), "Design innovation: a tool for value-adding to the Papua New Guinea balsa wood industry”, Journal of Design, Business \& Society, Vol. 2 No. 2, pp. 183-196, available: http://dx.doi.org/10.1386/dbs.2.2.183_1.

Livesey, F., Minshall, T. and Moultrie, J. (2006), "Investigating the technology-based innovation gap for the United Kingdom", Report to the Design Council. 
Maia, C. and Claro, J. (2013), "The role of a Proof of Concept Center in a university ecosystem: an exploratory study", The Journal of Technology Transfer, Vol. 38 No. 5, pp. 641-650, available: http://dx.doi.org/10.1007/s10961-0129246-y.

Mankins, J.C. (1995), “Technology readiness levels”, White Paper, April, 6.

Mansfield, E. and Lee, J.-Y. (1996), "The modern university: contributor to industrial innovation and recipient of industrial R\&D support”, Research policy, Vol. 25 No. 7, pp. 1047-1058, available: http://dx.doi.org/10.1016/S0048-7333(96)00893-1.

Markham, S.K. (2002), "Moving technologies from lab to market”, Research-Technology Management, Vol. 45 No. 6 , pp. 31-42, available: http://dx.doi.org/10.1080/08956308.2002.11671531.

Markham, S.K., Green, S.G. and Basu, R. (1991), "Champions and antagonists: Relationships with R\&D project characteristics and management”, Journal of Engineering and Technology Management, Vol. 8 No. 3-4, pp. 217 242, available: http://dx.doi.org/10.1016/0923-4748(91)90012-G.

Markman, G.D., Gianiodis, P.T., Phan, P.H. and Balkin, D.B. (2004) "Entrepreneurship from the ivory tower: Do incentive systems matter?", The Journal of Technology Transfer, Vol. 29 No. 3-4, pp. 353-364, available: http://dx.doi.org/10.1023/B:JOTT.0000034127.01889.86.

Markman, G.D., Gianiodis, P.T., Phan, P.H. and Balkin, D.B. (2005), "Innovation speed: Transferring university technology to market", Research policy, Vol. 34 No. 7, pp. 1058-1075, available: http://dx.doi.org/10.1016/j.respol.2005.05.007.

Minshall, T., Seldon, S. and Probert, D. (2007), "Commercializing a disruptive technology based upon University IP through Open Innovation: A case study of Cambridge Display Technology”, International Journal of Innovation and Technology Management, Vol. 4 No. 03, pp. 225-239, available: http://dx.doi.org/10.1142/S0219877007001107.

Moody, S. (1980), "The role of industrial design in technological innovation”, Design studies, Vol. 1 No. 6, pp. 329-339, available: http://dx.doi.org/10.1016/0142-694X(80)90039-3.

Moultrie, J. (2015), "Understanding and classifying the role of design demonstrators in scientific exploration", Technovation, Vol. 43, p. 1-16, available: http://dx.doi.org/10.1016/j.technovation.2015.05.002.

O'shea, R.P., Allen, T.J., Chevalier, A. and Roche, F. (2005), 'Entrepreneurial orientation, technology transfer and spinoff performance of US universities”, Research policy, Vol. 34 No. 7, pp. 994-1009, available: http://dx.doi.org/10.1016/j.respol.2005.05.011.

OECD (2017), “OECD Science”, Technology and Industry Scoreboard, 2017.

Phaal, R., O’Sullivan, E., Routley, M., Ford, S. and Probert, D. (2011), “A framework for mapping industrial emergence”, Technological forecasting and social change, Vol. 78 No. 2, pp. 217-230, available: http://dx.doi.org/10.1016/j.techfore.2010.06.018.

Roozenburg, N.F. and Eekels, J. (1995), Product design: fundamentals and methods, John Wiley \& Sons Inc.

Rust, C. (2004), "Design enquiry: Tacit knowledge and invention in science”, Design issues, Vol. 20 No. 4, pp. 76-85, available: http://dx.doi.org/10.1162/0747936042311959.

Siegel, D.S., Waldman, D. and Link, A. (2003), “Assessing the impact of organizational practices on the relative productivity of university technology transfer offices: an exploratory study", Research policy, Vol. 32 No.1, pp. 27-48, available: http://dx.doi.org/10.1016/S0048-7333(01)00196-2.

Siegel, D.S., Waldman, D.A., Atwater, L.E. and Link, A.N. (2004), "Toward a model of the effective transfer of scientific knowledge from academicians to practitioners: qualitative evidence from the commercialization of university technologies", Journal of Engineering and Technology Management, Vol. 21 No. 1-2, pp. 115-142, available: http://dx.doi.org/10.1016/j.jengtecman.2003.12.006.

Simeone, L., Secundo, G. and Schiuma, G. (2016) "Adopting a design approach to translate needs and interests of stakeholders in academic entrepreneurship: The MIT Senseable City Lab case”, Technovation, available: http://dx.doi.org/10.1016/j.technovation.2016.12.001.

Stember, M. (1991), "Advancing the social sciences through the interdisciplinary enterprise”, The Social Science Journal, Vol. 28 No. 1, pp. 1-14, available: http://dx.doi.org/10.1016/0362-3319(91)90040-B.

Thong, C. and Kuys, B. (2012), "A Empirical Study of Industrial Design Contribution to Advances in Timber Materials Science', in Advanced Materials Research”, Trans Tech Publ, pp. 248-253, available: http://dx.doi.org/10.4028/www.scientific.net/AMR.415-417.248.

Wessner, C.W. (2005), "Driving innovations across the valley of death”, Research-Technology Management, Vol. 48 No. 1, pp. 9-12, available: http://dx.doi.org/10.1080/08956308.2005.11657289.

Würmseher, M. (2017) “To each his own: Matching different entrepreneurial models to the academic scientist's individual needs", Technovation, Vol. 59, pp. 1-17, available: http://dx.doi.org/10.1016/j.technovation.2016.10.002.

Zappe, H. (2013) “Innovation: Bridging the market gap", Nature, Vol. 501 No.7468, p. 483, available: http://dx.doi.org/10.1038/501483a. 